\title{
Insights into Epoxy Network Nanostructural Heterogeneity using AFM-IR
}

DOI:

10.1021/acsami.5b10767

\section{Document Version}

Accepted author manuscript

Link to publication record in Manchester Research Explorer

\section{Citation for published version (APA):}

Morsch, S., Liu, Y., Lyon, S., \& Gibbon, S. (2015). Insights into Epoxy Network Nanostructural Heterogeneity using AFM-IR. A C S Applied Materials and Interfaces, 8(1), 959-966. https://doi.org/10.1021/acsami.5b10767

\section{Published in:}

A C S Applied Materials and Interfaces

\section{Citing this paper}

Please note that where the full-text provided on Manchester Research Explorer is the Author Accepted Manuscript or Proof version this may differ from the final Published version. If citing, it is advised that you check and use the publisher's definitive version.

\section{General rights}

Copyright and moral rights for the publications made accessible in the Research Explorer are retained by the authors and/or other copyright owners and it is a condition of accessing publications that users recognise and abide by the legal requirements associated with these rights.

\section{Takedown policy}

If you believe that this document breaches copyright please refer to the University of Manchester's Takedown Procedures [http://man.ac.uk/04Y6Bo] or contact uml.scholarlycommunications@manchester.ac.uk providing relevant details, so we can investigate your claim.

\section{OPEN ACCESS}




\section{Insights into Epoxy Network Nanostructural Heterogeneity using AFM-IR}

Suzanne Morsch ${ }^{*},{ }_{1}$ Yanwen Liu ${ }^{1}$, Stuart B. Lyon, ${ }^{1}$ Simon R. Gibbon ${ }^{2}$

${ }^{1}$ Corrosion and Protection Centre,

School of Materials,

The University of Manchester,

The Mill,

Sackville St,

Manchester, M13 9PL, UK

${ }^{2}$ AkzoNobel Supply Chain, Research \& Development, Stoneygate Lane,

Felling,

Gateshead,

Tyne \& Wear, NE10 0JY, UK

${ }^{*}$ To whom correspondence should be addressed. Suzanne.morsch@manchester.ac.uk tel: +44 1613062914 


\section{ABSTRACT}

The first direct observation of a chemically heterogeneous nanostructure within an epoxy resin is reported. Epoxy resins comprise the matrix component of many high performance composites, coatings and adhesives, yet the molecular network structure that underpins the performance of these industrially essential materials is not well understood. Internal nodular morphologies have repeatedly been reported for epoxy resins analysed using SEM or AFM, yet the origin of these features remains a contentious subject, and epoxies are still commonly assumed to be chemically homogeneous. Uniquely, in this contribution we use the recently developed AFM-IR technique to eliminate previous differences in interpretation, and establish that nodule features correspond to heterogeneous network connectivity within an epoxy phenolic formulation.

\section{KEYWORDS}

Epoxy resin; Nanostructure; Heterogeneity; AFM-IR, Network formation. 


\section{INTRODUCTION}

Network forming polymers are ubiquitous in modern society, forming the primary matrix component in many paints, ${ }^{1}$ adhesives ${ }^{2}$ and composites ${ }^{3,4}$ used in industries such as aerospace engineering,$^{5,6,7}$ marine coatings, ${ }^{8}$ microelectronics, ${ }^{9,10}$ and packaging ${ }^{11}$. Critical properties such as the chemical resistance, ${ }^{12}$ corrosion resistance ${ }^{13,14,15}$ thermal stability ${ }^{16,17}$ and mechanical strength $^{18}$ offered by these materials are well known to depend on the network structure of the supporting resin. A highly desirable goal in formulation is therefore the controlled synthesis of well-defined network structures, yet the macromolecular architecture underpinning the performance of these materials remains largely unresolved.

In the case of epoxy resins, inhomogeneous network formation has historically been proposed on the basis of microscopic studies and bulk scattering techniques, which support a view of cured networks comprised of highly cross-linked nanoscale domains embedded in a lightly cured matrix. ${ }^{19,20,21,22,23,24}$ Heterogeneous cross-linking on this scale is expected to provide low energy pathways through the resin, yielding a structural basis for the relatively low fracture toughness of epoxy materials. ${ }^{25,26}$ Indeed it has recently been shown that the bulk toughness, solvent resistance, $T_{g}$, compressive strain to failure and ductility of formation improve when narrow molecular weight distributions are maintained during the cure of epoxydicyanodiamide resins. ${ }^{27}$ Nonetheless, the presence and origin of such internal nanostructure has remained a point of active debate in the literature. For example, early evidence for highly cross-linked 'nodule' features was predominately obtained using electron microscopy, where internal structures were exposed by fracturing. However, in a seminal paper Dušek argued that comparably rough morphologies could be observed in electron micrographs of plasma-etched linear polymers such as polystyrene and polymethyl methacrylate, and thus concluded that nodules are a general feature of homogeneous glassy polymers, or else form as a consequence of sample preparation. ${ }^{28}$ More recently, examination of fracture surfaces has become possible under ambient conditions (i.e., circumventing any sample preparation effects) using the atomic force microscope (AFM), and numerous reports have emerged of nodular morphologies 
detected in tapping mode height or phase images. ${ }^{26,29,30,31}$ However, Duchet et al. countered that such features may be attributed to imaging artefacts generated by a blunt SPM probe tip scanning over rough surfaces, and a similar argument has recently been made for peakforce tapping mode modulus maps showing an apparently heterogeneous nanostructure for epoxy amine fracture surfaces. ${ }^{32,33}$

These differences in interpretation are unsurprising, given that the evidence for heterogeneous network formation has largely been limited to topographical measurements of fracture interfaces. Whilst small angle neutron or x-ray scattering studies can be found to support resin heterogeneity, the link between nanoscale morphological features and chemical heterogeneity has not been established. ${ }^{34,35}$ In light of this, the recent advent of nanoscale vibrational spectroscopy in the form of AFM-IR represents a unique opportunity to interrogate chemical functionality at sub-diffraction limit resolution, enabling direct macromolecular characterisation. In the present study, a combination of AFM and SEM techniques are first used to systematically confirm the heterogeneous internal morphology for model epoxy-phenolic resins, then chemical heterogeneity is for the first time assessed directly, using the recently developed nanoscale infrared analysis technique (AFM-IR), Schemes 1 and 2.

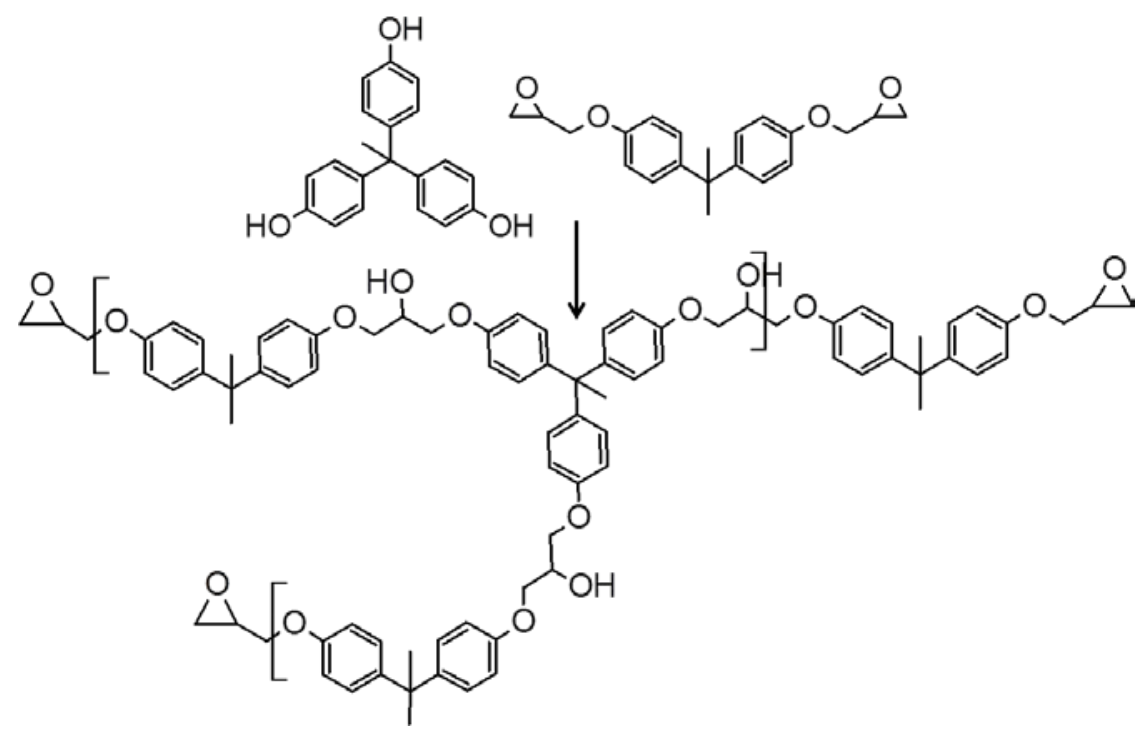

Scheme 1. The cross-linking reaction between bisphenol-A diglycidyl ether and 1,1,1-tris(4hydroxyphenyl)ethane catalysed by tetrabutylphosphonium bromide. 


\section{EXPERIMENTAL}

\subsection{Sample preparation}

$3.06 \mathrm{~g}$ (10 mmol) 1,1,1-tris(4-hydroxyphenyl)ethane (99\%, Sigma-Aldrich) and $0.01 \mathrm{~g}-0.10 \mathrm{~g}$ (0.03 mmol - $0.3 \mathrm{mmol}$ corresponding to $0.1 \%$ - $1.0 \%$ ) tetrabutylphosphonium bromide (+98 \%, Sigma-Aldrich) were dissolved in $6.0 \mathrm{~g}$ acetone (> $98 \%$, Fisher). $5.16 \mathrm{~g}$ (15 mmol) bisphenol-A diglycidyl ether (DER332, epoxide equivalent weight 172-176 $\mathrm{g} \mathrm{mol}^{-1}$, Sigma-Aldrich) was then added and stirred until dissolved. This solution was coated onto pre-scored electrolytic chromecoated steel pieces $\left(25 \mathrm{~cm}^{2}\right)$ which had been degreased by sonic cleaning in ethanol (Fisher Scientific, >99\%). Coating was performed using an automated bar coater (Model 4340, Elcometer, UK) fitted with a $100 \mu \mathrm{m}$ spiral bar. Samples were then cured by placing in an oven maintained at $150{ }^{\circ} \mathrm{C}$ for prescribed time intervals $(10-60 \mathrm{~min})$ and stored at $-4{ }^{\circ} \mathrm{C}$ prior to analysis. Polystyrene control samples (Sigma Aldrich, analytical standard, average $M_{w} 290,000$ ) were bar coated in the same manner from $5 \% \mathrm{w} / \mathrm{w}$ solutions in toluene (Fisher Scientific, >99\%) and then cryogenically fractured prior to analysis.

\subsection{Characterization Techniques}

Atomic force microscopy images were collected using a Multimode 8 (Bruker, Santa Barbara) operating in peakforce tapping mode using a Pt-Ir coated probe (nominal spring constant $2 \mathrm{~N} / \mathrm{m}$, nominal resonant frequency of $80 \mathrm{kHz}$, Bruker). Scanning electron micrographs (Evo 50, Zeiss) were gathered under an acceleration voltage of $10 \mathrm{kV}$ after gold sputter coating (PECS Model 682, Gatan Inc.).

Bulk infrared spectra were obtained from 64 co-averages collected in ATR mode using an FTIR spectrometer (Nicolet 5700 spectrometer, Thermo Electron Corp.) operating at $4 \mathrm{~cm}^{-1}$ resolution across the $500-4000 \mathrm{~cm}^{-1}$ range.

Nanoscale infrared analysis was performed on a NanolR2 system (Anasys Instruments) operating with top-down illumination. For AFM-IR, polymer sections of $100 \mathrm{~nm}$ nominal 
thickness were prepared by a Leica EM UC6 ultramicrotome with a diamond knife and collected on TEM grids. These were then floated on a droplet of deionised water on a ZnS substrate (Anasys Instruments). Upon evaporation of the droplet, TEM grids were removed. Specimen sections remained on the ZnS surface which was allowed to dry for $>16 \mathrm{~h}$ in a desiccator prior to analysis. During AFM-IR, the sample is subjected to rapid pulses (10 ns duration at a repetition rate of $1 \mathrm{KHz}$ ) from a tuneable infrared source (optical parametric oscillator). ${ }^{36}$ Absorbance of infrared radiation induces abrupt thermal expansion of the sample, and this is detected by deflection of an AFM probe in contact with the surface. The recorded AFM-IR signal is either the maximum of peak-to-peak deflection during the cantilever ring-down corresponding to IR pulses, or the amplitude of induced oscillation after fast Fourier transform, Scheme 2. It has been shown that plotting these signals as a function of IR wavelength yields spectra closely matched to those obtained by macroscopic transmission-mode FTIR. ${ }^{37}$ Furthermore, since the IR pulse (10 ns duration), thermal expansion, and damping down of the induced oscillation occur on a faster timescale than the feedback electronics of the AFM, simultaneous contactmode topographical measurement and IR absorbance mapping can be performed at a given wavelength. ${ }^{38,39,40,41}$ For the present study, AFM-IR images were collected in contact mode at a scan rate of $0.1 \mathrm{~Hz}$ using a gold-coated silicon nitride probe $(0.07-0.4 \mathrm{~N} / \mathrm{m}$ spring constant, 13 $\pm 4 \mathrm{kHz}$ resonant frequency, Anasys Instruments). For mapping, peak-to-peak deflection was recorded at a given wavelength using 16 co-averages for 1024 points per 150 scan lines. Spectra were obtained using 1024 co-averages for each data point. 


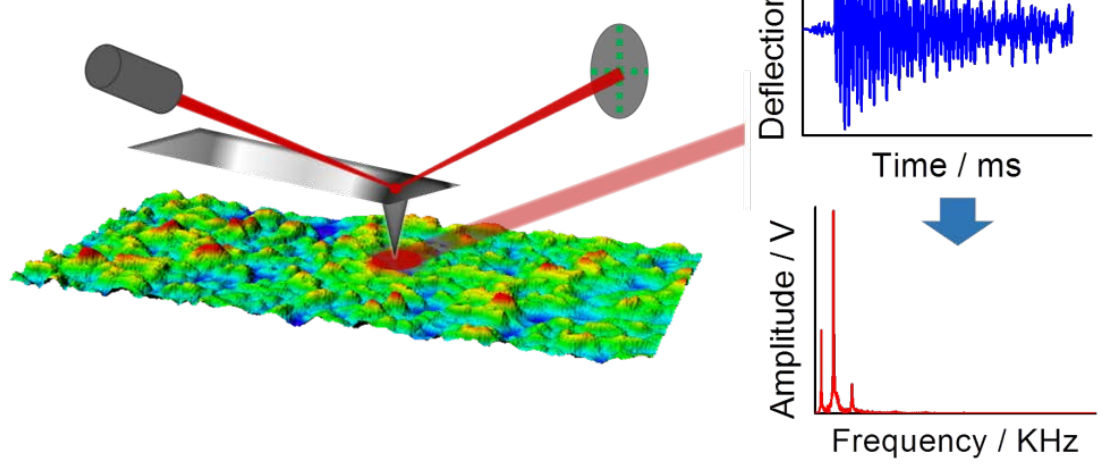

Scheme 2. The AFM-IR experiment with top-down illumination. The IR source is pulsed, inducing rapid thermal expansion of the sample, which is detected by deflection of the AFM probe cantilever. The recorded AFM-IR signal is either given as the maximum peak-to-peak deflection during the cantilever ring-down, or the amplitude at a given frequency following a fast Fourier transform of the deflection signal. 


\section{RESULTS}

\subsection{Fracture interface morphology}

Peakforce AFM analysis was performed immediately after epoxy-phenolic samples had been cryogenically fractured. For specimens prepared using lowered catalyst content $(0.1 \%)$ the cure reaction was sufficiently slow at $150{ }^{\circ} \mathrm{C}$ for the development of a heterogeneous morphology to be directly observed in successive samples, Figure 1 . Since it has previously been suggested that nodular features observed in AFM micrographs correspond to tip artefacts, fresh AFM probes were employed for each specimen. In addition, fracture surfaces were analysed using scanning electron microscopy (SEM), yielding electron micrographs consistent with the AFM profiles, Figure 2. This demonstrates the ability of AFM analysis to resolve these nanoscale morphological features, and furthermore, since samples cured for 10 min appear smooth and homogeneous in all micrographs, sample preparation effects can be discounted as a source of imaging artefact, Figures 1 and 2.

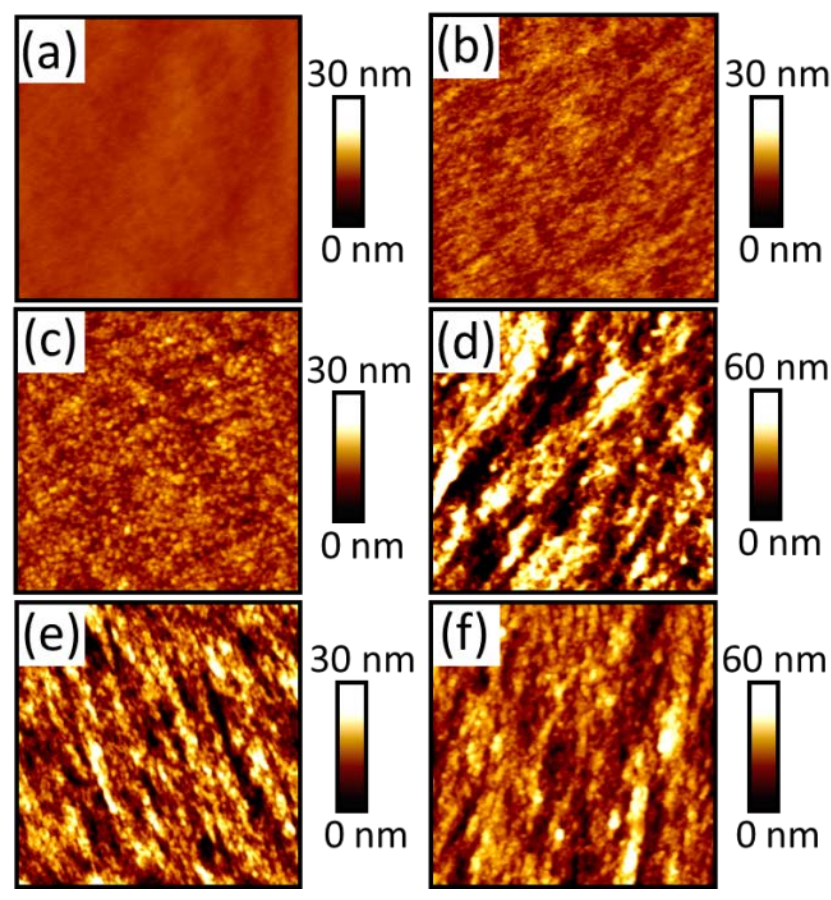

Figure 1. $2 \mu \mathrm{m} \times 2 \mu \mathrm{m}$ peakforce tapping mode AFM height images of fracture surfaces of epoxy phenolic resin cured with $0.1 \%$ catalyst at $150{ }^{\circ} \mathrm{C}$ for (a) $10 \mathrm{~min}$; (b) $20 \mathrm{~min}$; (c) $30 \mathrm{~min}$; (d) $40 \mathrm{~min}$; (e) $50 \mathrm{~min}$ and (f) $60 \mathrm{~min}$. 


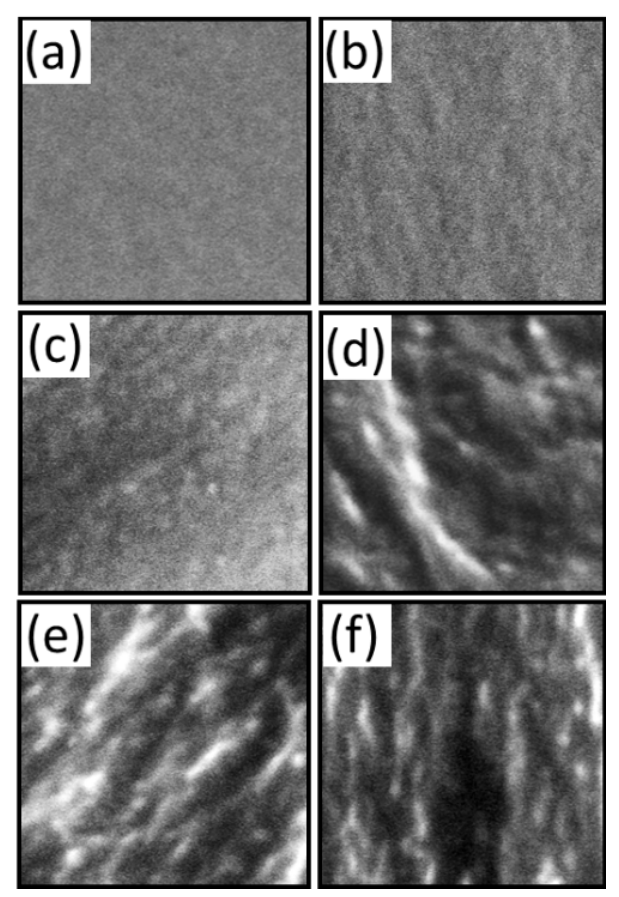

Figure 2. $2 \mu \mathrm{m} \times 2 \mu \mathrm{m}$ SEM images of epoxy phenolic resin fracture surfaces cured using $0.1 \%$ catalyst at $150{ }^{\circ} \mathrm{C}$ for (a) $10 \mathrm{~min}$; (b) $20 \mathrm{~min}$; (c) $30 \mathrm{~min}$; (d) $40 \mathrm{~min}$; (e) $50 \mathrm{~min}$ and (f) $60 \mathrm{~min}$.

It can be seen that upon curing, fracture interfaces progressively roughen until a nodular morphology develops (after $30 \mathrm{~min}$ ), which then remains unchanged on further curing, Figure 1. This is in keeping with results reported by Sahagun et al. for epoxy amine systems, where the size of heterogeneous domains was found to be dependent on cross-linking reactions prior to gelation, and post-cure annealing had no further effect. ${ }^{26}$ Examination of resins cured in the presence of $0.5 \%$ catalytic accelerator (under otherwise identical conditions) revealed that a comparable nodular morphology was established after a shorter curing period (20 min), demonstrating that a heterogeneous network developed more rapidly, Figure 3 . For samples cured using a still higher content of tetrabutylphosphonium bromide catalyst (1.0\%), fracture surfaces were found to display heterogeneous nodular morphologies regardless of cure time (> $10 \mathrm{~min})$, Figure 4. Gel points were estimated for the model epoxy-phenolic resins by weight loss measurements after warming for $1 \mathrm{~h}$ in acetone. Threshold cure times were found after which no dissolution was measurable, and these were $10 \mathrm{~min}, 20 \mathrm{~min}$ and $40 \mathrm{~min}$ for specimens prepared using $1.0 \%, 0.5 \%$ and $0.1 \%$ catalyst respectively. These times correspond to the emergence of a fixed nodular topography at the fracture interface, providing further evidence 
that the development of network heterogeneity corresponds to pre-gelation reactions, analogous to non-catalysed epoxy-amine systems. Indeed, resins cured in the absence of catalytic accelerator species (at $250{ }^{\circ} \mathrm{C}$ ) were also found to develop heterogeneous internal morphologies, indicating that whilst catalytic content governs the rate of heterogeneous network development, its nature remains unaffected, Figure 4.

Finally, several authors have reported that the topography of epoxy fracture interfaces can be reproduced using linear polymers, and have therefore stated that these are a general feature of glassy polymers, or else a result of the fracturing process. ${ }^{32,42}$ To this end, we prepared a control sample using commercially available polystyrene. In contrast to previous reports, the polystyrene fracture surface was measured to be homogeneous and smooth by AFM, Figure $4 f^{32,42}$

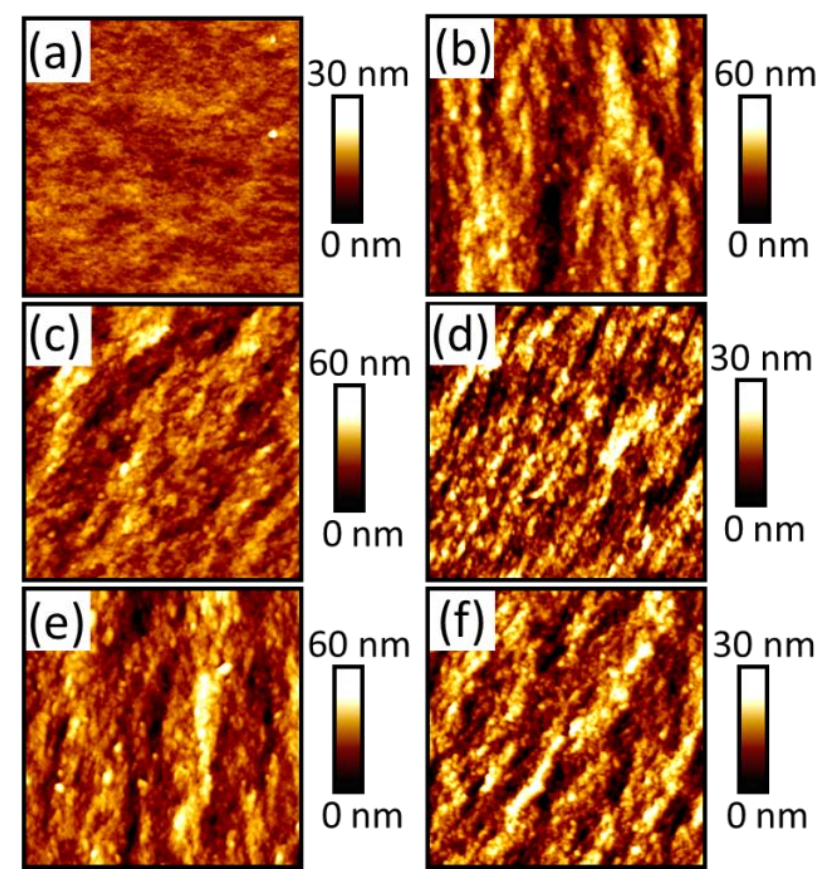

Figure 3. $2 \mu \mathrm{m} \times 2 \mu \mathrm{m}$ peakforce tapping mode AFM height images of fracture surfaces of epoxy phenolic resin cured with $0.5 \%$ catalyst at $150^{\circ} \mathrm{C}$ for (a) $10 \mathrm{~min}$; (b) $20 \mathrm{~min}$; (c) $30 \mathrm{~min}$; (d) $40 \mathrm{~min}$; (e) $50 \mathrm{~min}$ and (f) $60 \mathrm{~min}$. 


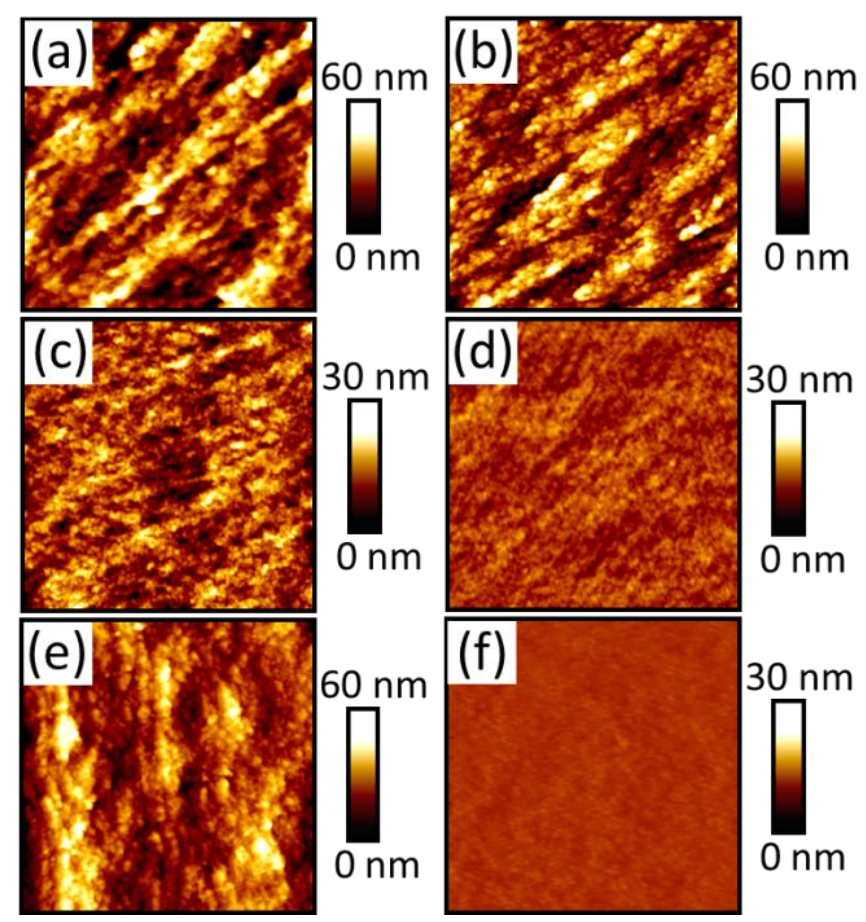

Figure 4. $2 \mu \mathrm{m} \times 2 \mu \mathrm{m}$ peakforce tapping mode AFM height images of fracture surfaces of epoxy phenolic resin cured with $1 \%$ catalyst at $150^{\circ} \mathrm{C}$ for (a) $10 \mathrm{~min}$; (b) $20 \mathrm{~min}$ and (c) $60 \mathrm{~min}$; epoxy phenolic resin cured in the absence of catalyst at $250^{\circ} \mathrm{C}$ for (d) $10 \mathrm{~min}$ and (e) $60 \mathrm{~min}$ and (f) fractured polystyrene.

\subsection{AFM-IR Analysis}

Prior to AFM-IR experiments, FTIR analysis of the cure reaction was undertaken in order to assign infrared peaks to the epoxy-phenolic reaction. Characteristic epoxy-phenolic absorbance peaks observed in spectra include the aryl C-O stretch at $1180 \mathrm{~cm}^{-1}$ (associated with aromatic ethers and phenolic species), the $\left(\mathrm{CH}_{3}\right)_{2}$ gem dimethyl $\mathrm{C}-\mathrm{H}$ deformation at $1364 \mathrm{~cm}^{-1}$ and 1381 $\mathrm{cm}^{-1}$ and aromatic doublet peaks at $1459 \mathrm{~cm}^{-1}, 1504 \mathrm{~cm}^{-1}, 1580 \mathrm{~cm}^{-1}$ and $1604 \mathrm{~cm}^{-1}$. 43,44,45,46 It can be seen that the relative intensity of these peaks remained unchanged with respect to cure time, Figure 5. The shape of the broad absorbance centred at $1244 \mathrm{~cm}^{-1}$ does however fluctuate (most clearly between 5 and 10 min cure time in the presence of $0.1 \%$ catalyst, Figures $5 a$ and 5b). This is expected since the band corresponds to overlapping absorbance associated with the C-O stretch for phenolic and aromatic ether functionalities, and may therefore be associated with both residual unreacted functional groups and polymeric functionality. Moreover, during curing, consumption of the epoxy moiety was verified by the disappearance of absorbance at $916 \mathrm{~cm}^{-1}$ (asymmetric oxirane ring deformation, clearly observed for curing times of $<20$ min in 
the presence of $0.1 \%$ catalyst, Figure 5). This is accompanied by the appearance of a peak at $1116 \mathrm{~cm}^{-1}$, signifying the generation of secondary hydroxyl groups (alkyl hydroxyl out of phase C-C-O stretch). The curing process can therefore be monitored by integration and normalization of these bands, Figure 6 . It is noteworthy that a 1:1 relationship exists between consumption of the epoxy moiety and emergence of the hydroxyl absorbance, effectively discounting homopolymerization of the epoxy as a side reaction leading to phase separation (an alternative explanation for the evolution of a nodular morphology).

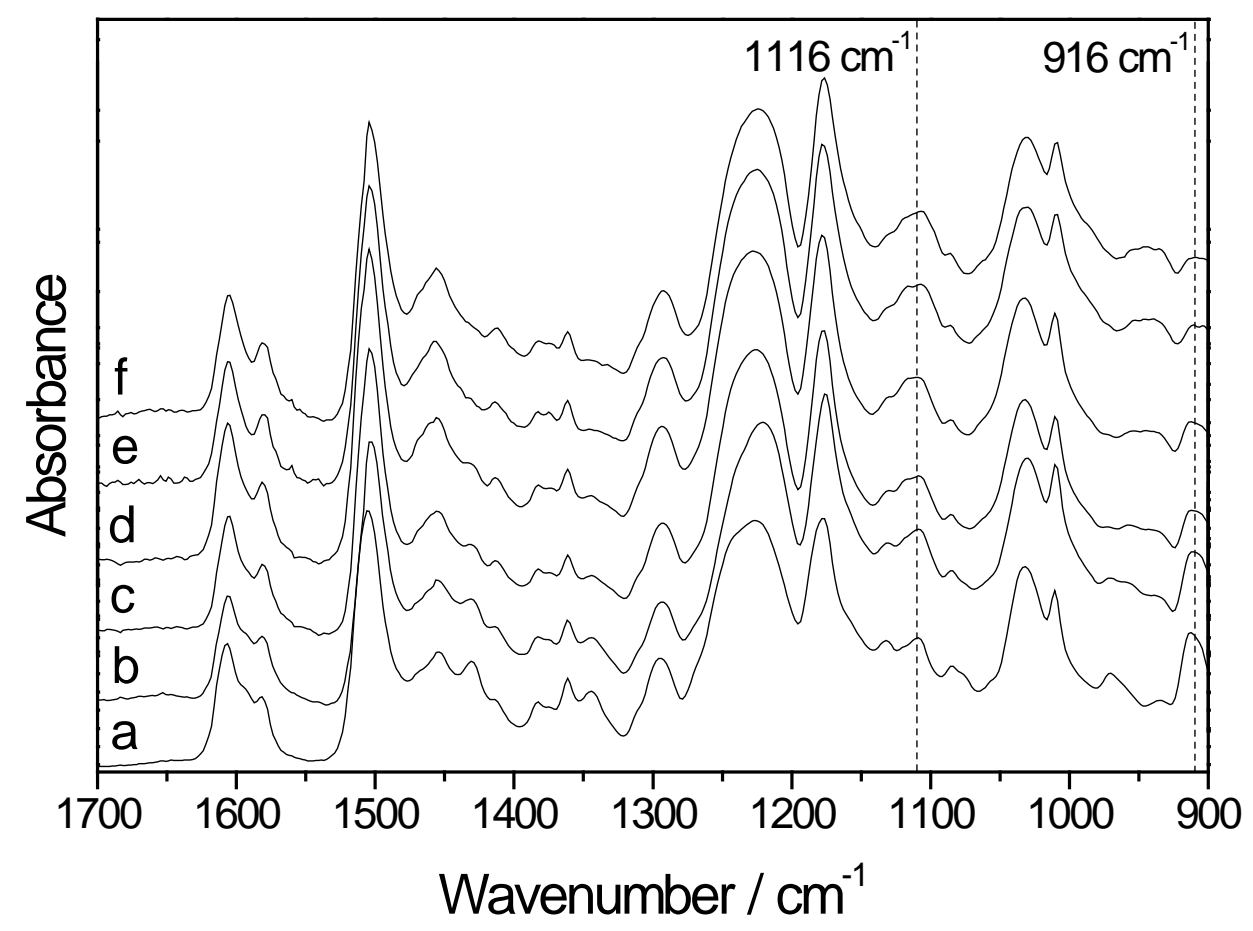

Figure 5. ATR-FTIR spectra for model epoxy-phenolic coating cured with $0.1 \%$ catalyst at $150{ }^{\circ} \mathrm{C}$ for (a) $5 \mathrm{~min}$; (b) $10 \mathrm{~min}$; (c) $15 \mathrm{~min}$; (d) $20 \mathrm{~min}$; (e) $25 \mathrm{~min}$ and (f) $30 \mathrm{~min}$. 

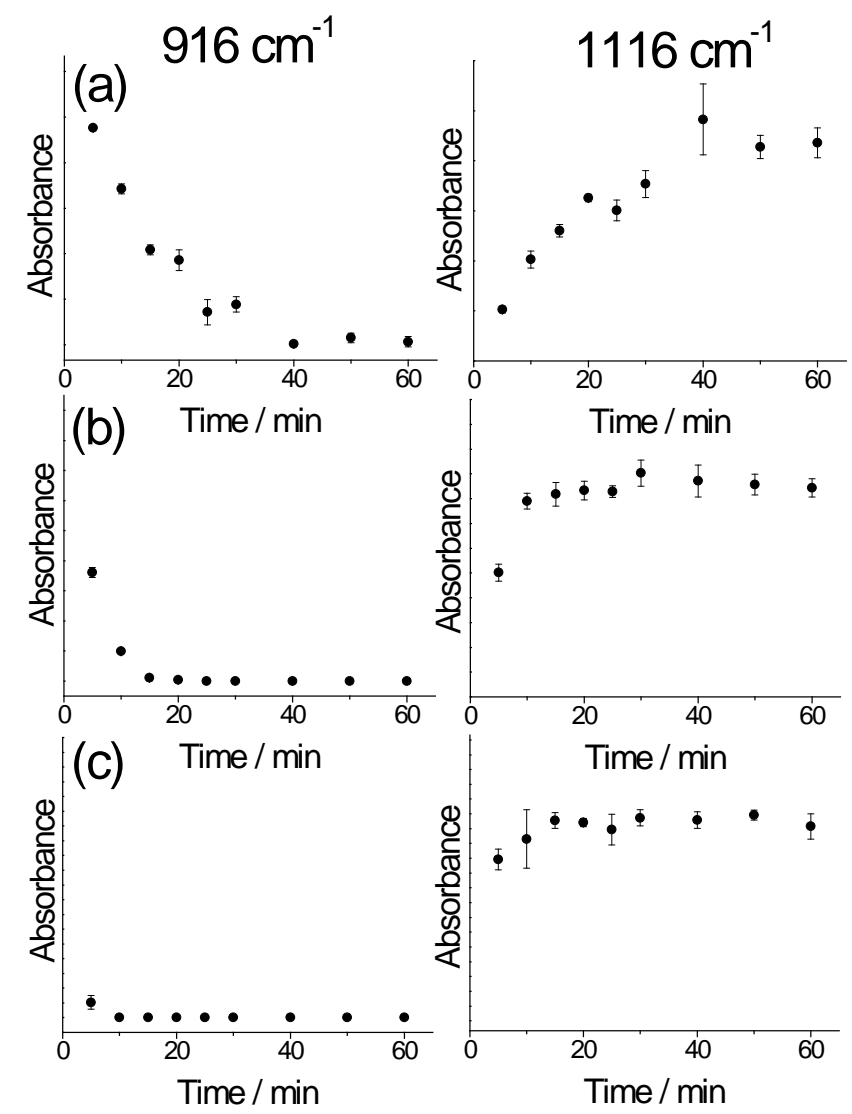

Figure 6. FTIR peak areas for epoxy-phenolic resins as a function of cure time at $150{ }^{\circ} \mathrm{C}$ of the epoxy peak at $916 \mathrm{~cm}^{-1}$ (normalised relative to absorbance at $1180 \mathrm{~cm}^{-1}$ ) and the hydroxyl stretch at $1116 \mathrm{~cm}^{-1}$ (normalised relative to absorbance at $1180 \mathrm{~cm}^{-1}$ ). Coatings were cured in the presence of (a) $0.1 \%$ catalyst; (b) $0.5 \%$ catalyst and (c) $1.0 \%$ catalyst. Error bars correspond to 1 standard deviation for 5 individual measurements.

In order to obtain high-resolution AFM-IR measurements, ultrathin sections of the epoxyphenolic resin (100 nm) were prepared by ultramicrotome and deposited onto a ZnS substrate. Infrared spectra associated with the AFM probe tip location were then collected by stepping the wavelength of pulsed incident radiation through the mid IR range. In keeping with previous reports of AFM-IR analysis for nanofilm specimens, the maximum peak-to-peak probe deflection was recorded. ${ }^{47}$ Despite the small sampling volume, AFM-IR spectra displayed peak positions and shapes which closely match the fingerprint region of bulk ATR FTIR spectra, Figures 5 and 7. Localised infrared spectra gathered with $40 \mathrm{~nm}$ lateral spacing revealed variation in the peak intensities associated with the epoxy-phenolic cure reaction at $1116 \mathrm{~cm}^{-1}$ and $1244 \mathrm{~cm}^{-1}$ 
(spectra are normalized to the aromatic peak at $1504 \mathrm{~cm}^{-1}$ ), Figure 7. This is a strong indication of heterogeneous curing.

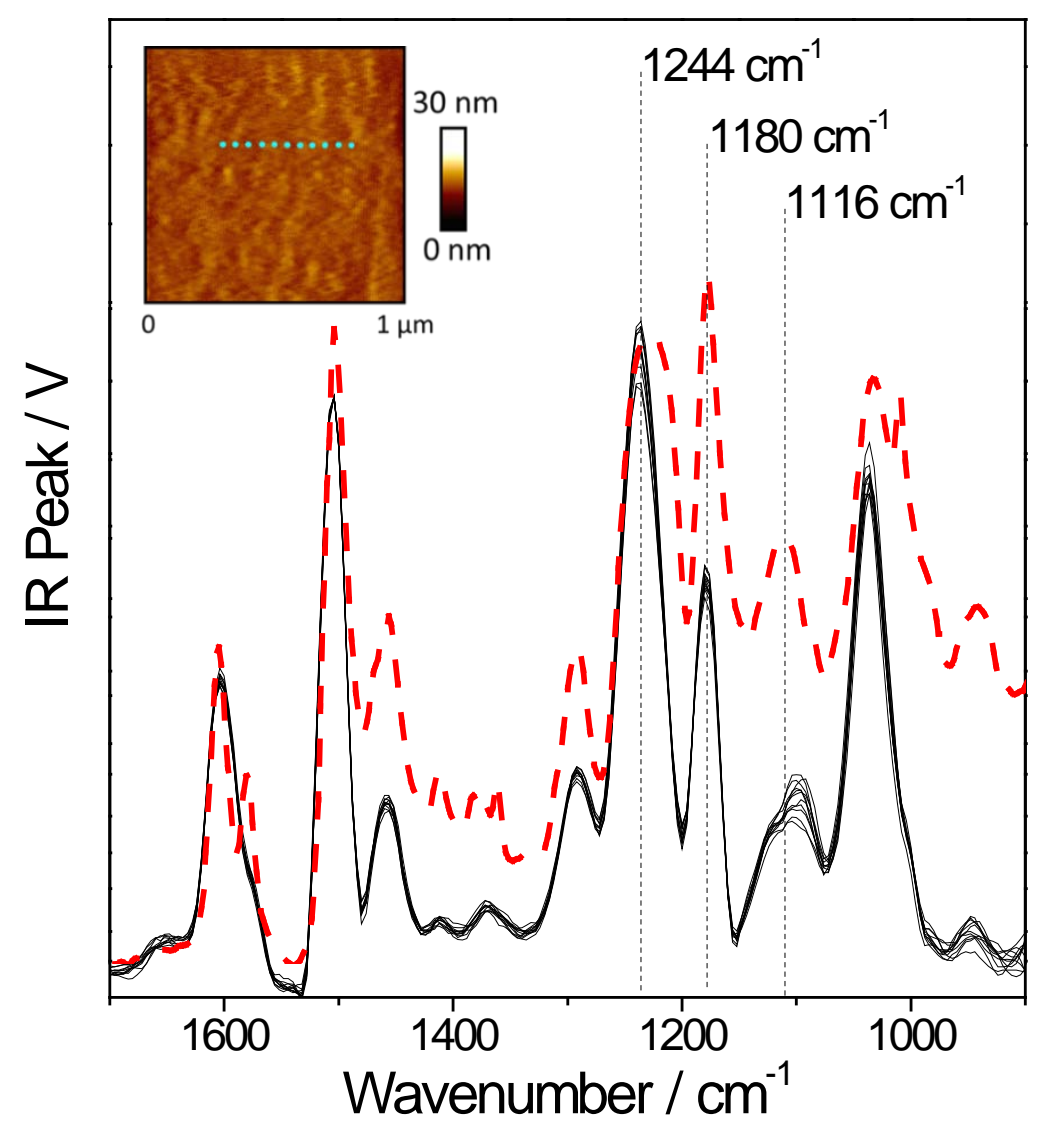

Figure 7. AFM-IR fingerprint region spectra obtained with $40 \mathrm{~nm}$ lateral spacing for $100 \mathrm{~nm}$ thick section of epoxy-phenolic resin cured for 10 min with $1 \%$ catalyst (black solid lines), and bulk ATR-IR spectrum for 60 min cured epoxy-phenolic coating cured with $1 \%$ catalyst (red dashed line). Inset: $1 \mu \mathrm{m} \times 1 \mu \mathrm{m}$ AFM-IR height image for $100 \mathrm{~nm}$ thick microtomed section of epoxy-phenolic resin, where cyan markers indicate the location of AFM-IR spectra.

AFM-IR mapping was performed to provide a detailed picture of chemical heterogeneity. For the microtomed epoxy-phenolic sections, contact mode height images revealed flattened regions, where the topography is characteristic of deformation during cutting, Figures 7 and 8 , and heterogeneous regions displaying an intact nodular morphology, in keeping with peakforce tapping mode profiles, Figure 9. Since the relative infrared signal is known to depend on sample thickness, ${ }^{36}$ infrared spectra and absorbance mapping at $1116 \mathrm{~cm}^{-1}$ (corresponding to the alkyl out of phase C-C-O stretch of secondary hydroxyl groups generated during cure) was initially performed on flattened regions. This revealed variations in the peak-to-peak signal intensity on 
the nanoscale, consistent with the 'smeared' appearance of the topography. Moreover, for intact nodular regions, the variation in IR peak signal at $1116 \mathrm{~cm}^{-1}$ could clearly be seen to occur at a length scale consistent with nodules, Figure 9. To ensure this is not due to fluctuating sample thickness, mapping was also performed at $1244 \mathrm{~cm}^{-1}$ and $1180 \mathrm{~cm}^{-1}$. At $1244 \mathrm{~cm}^{-1}$ the signal varied across the sample, whereas maps gathered at $1180 \mathrm{~cm}^{-1}$ (corresponding to an absorbance peak of comparable intensity in the AFM-IR spectra) were featureless, further demonstrating that the detected peak-to-peak signal did not correspond to fluctuations in thickness or contact area between the probe and sample surface.
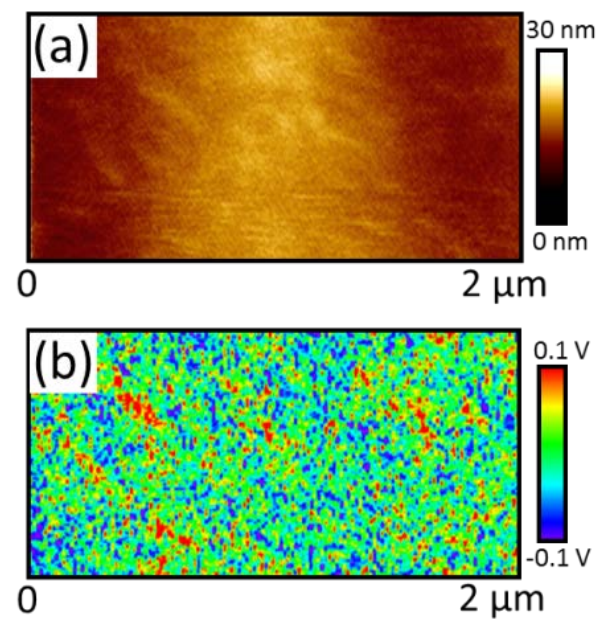

Figure 8. $2 \mu \mathrm{m} \times 1 \mu \mathrm{m}$ AFM-IR images of $100 \mathrm{~nm}$ thick microtomed section of epoxy-phenolic resin cured at $150{ }^{\circ} \mathrm{C}$ for 10 min with $1 \%$ catalyst: (a) height and (b) corresponding map of peak-to-peak IR-induced deflection following irradiation at $1116 \mathrm{~cm}^{-1}$. 

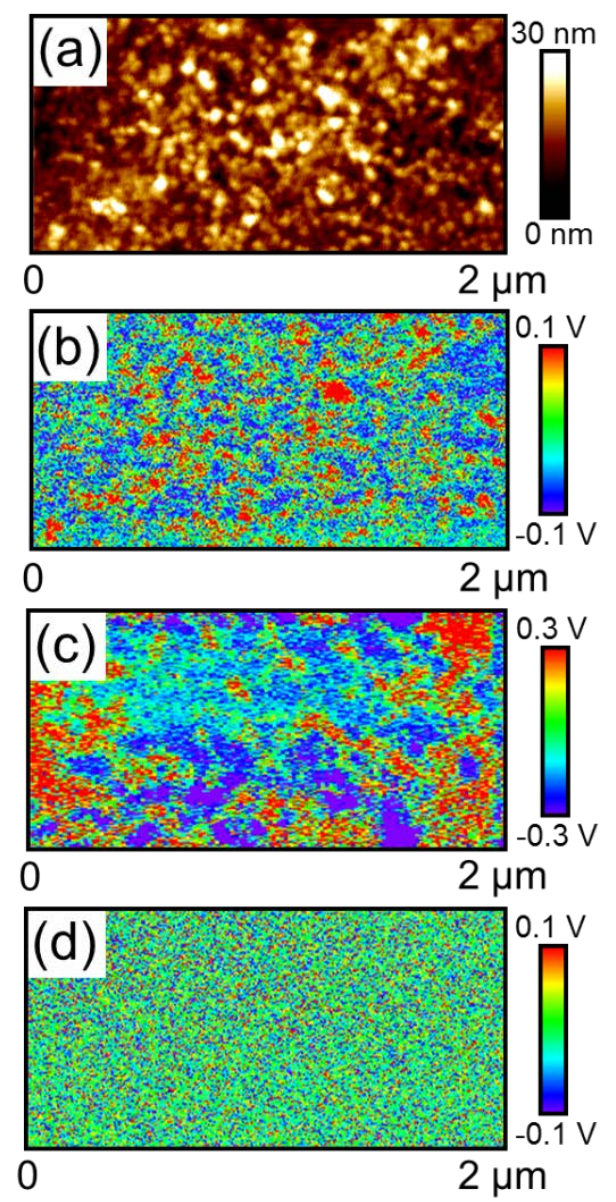

Figure 9. $2 \mu \mathrm{m} \times 1 \mu \mathrm{m}$ AFM-IR images of $100 \mathrm{~nm}$ thick microtomed section of epoxy-phenolic resin cured at $150{ }^{\circ} \mathrm{C}$ for 10 min with $1 \%$ catalyst: (a) height and corresponding maps of peak-to-peak IR-induced deflection following irradiation at (b) $1116 \mathrm{~cm}^{-1}$; (c) $1244 \mathrm{~cm}^{-1}$ and (d) $1180 \mathrm{~cm}^{-1}$. IR maps have been flattened line-by-line to show only localised fluctuations in the deflection signal. 


\section{DISCUSSION}

Numerous studies have previously described the internal nanostructure of epoxy amine resins, considered to develop during the pre-gelation stage of cure and correspond to fluctuations in cross-linking density. ${ }^{19,20,21,22,23,24,48,49}$ The establishment of a nodular morphology in the present work (and its unchanging nature post gelation) supports a comparable nanostructure in the case of epoxy-phenolic resins. Previously, only swelling and leaching experiments have provided (indirect) evidence for chemical heterogeneity within epoxy resins on this scale. ${ }^{19,50}$ In contrast, we were able to utilise the AFM-IR technique to provide direct, unambiguous evidence for chemical heterogeneity associated with curing. This is significant for a host of applications reliant on the robust mechanical and barrier properties of epoxy resins, since heterogeneous network formation is expected to determine the physicochemical properties of cured resin materials.

A further important finding is the unchanged heterogeneous resin morphology in relation to catalytic content. The majority of previous studies have focussed on un-catalysed model epoxy-

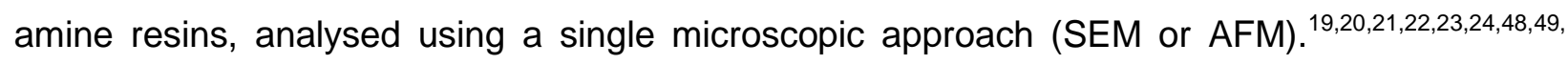
Little attention has been given to epoxy-phenolic resins, which are ordinarily cured in the presence of a catalytic accelerator. This is despite their widespread use as food-contact barrier coatings and encapsulation of semi-conductor devices, where heterogeneous network structure may determine performance, since small molecule transport is closely related to network crosslinking densities. ${ }^{51,52,53}$ Dušek has previously proposed that catalysis of epoxy network formation may promote cyclization during the cure, forming the basis of any heterogeneous structure detected. ${ }^{28,42}$ In the present case, such a mechanism can be discounted since catalytic content has no effect on heterogeneous domain size, and specimens cured in the absence of catalytic species develop comparable morphologies, Figures 1-4. Furthermore, any contribution of cyclization reactions (resulting in an increased proportion of dangling chain ends) would be expected to yield more marked heterogeneity for linear polymers generated by radical chain growth polymerisation. ${ }^{42}$ However, in the present study polystyrene fracture surfaces prepared 
in an identical manner to the epoxy-phenolic specimens were found to be smooth and homogeneous.

An alternative explanation for the internal nanostructure of epoxy phenolic resins can be found in the early mechanistic interpretations given for nodular epoxy amine systems. These entailed spontaneous development of impermeable nanogel particles during the early stages of cure, yielding densely cross-linked nodules embedded within a partially cured polymer matrix. ${ }^{19,29,54}$ This hypothesis (and the accompanying chemical heterogeneity within epoxy networks) was rejected by Dušek and others based on bulk scattering experiments and thermal analysis, where no evidence was found to support the formation of a two-phase material. ${ }^{42,55}$ In the present study, a direct comparison of SEM and AFM imaging was undertaken, and it is clear that whilst SEM imaging resolved some surface features (giving the appearance of isolated nodules), the more detailed profiles gathered using AFM indicate that samples are comprised of fused globular structures. Comparable morphologies have recently been reported for epoxy amine systems analysed using AFM, and these concur with early electron microscopy reports. ${ }^{26,30,56}$ It can be envisioned that such a 'fused nodule' nanostructure may correspond to a continuous distribution of bulk physical properties (e.g., broad thermal transitions characteristic of epoxy materials) rather than behaving as a discrete two-phase system. A network formation mechanism in keeping with these results was recently proposed by Sahagun et al. on the basis of competing cross-linking reactions and linear addition to growing chain ends, coupled with the preferential combination of larger oligomers (i.e., macromolecules with higher functionality) during initial stages of the cure. ${ }^{26}$ In this scenario, fluctuations in cross-linking density arise spontaneously according to the relative kinetics of the cross-linking and linear addition reactions. The unchanged morphology of heterogeneous samples in the present study can then be understood, since phosphonium catalysts are known to be highly selective for the epoxyphenolic reaction (as opposed to cross-linking through generated secondary hydroxyls) ${ }^{57}$ Thus, the ratio between cross-linking and linear addition reactions during the cure is primarily determined by the structure (functionality) of the epoxy and phenolic reagents rather than the catalytic content. 


\section{CONCLUSIONS}

Chemical heterogeneity has, for the first time, been shown to be the basis of the characteristic nodular structures found within epoxy resins. Uniquely, AFM-IR was applied to establish that inhomogenous curing occurs at the nanoscale within these materials. The development of network heterogeneity occurred independently of catalytic effects, and was shown to be controlled only by the underlying polymerisation reactions, where catalyst content and cure conditions affect the rate of network formation, but not its final form.

\section{ACKNOWLEDGEMENTS}

S. Morsch is grateful to AkzoNobel for financial support and materials. 


\section{REFERENCES}

(1) Martí, M.; Molina, L.; Alemán, C.; Armelin, E. Novel Epoxy Coating Based on DMSO as a Green Solvent, Reducing Drastically the Volatile Organic Compound Content and Using Conducting Polymers as a Non-Toxic Anticorrosive Pigment. ACS Sustainable Chem. Eng. 2013, 1, 1609-1618.

(2) Ji, Y.-H.; Liu, Y.; Huang, G.-W.; Shen, X.-J.; Xiao, H.-M.; Fu, S.-Y. Ternary Ag/Epoxy Adhesive with Excellent Overall Performance. ACS Appl. Mater. Interfaces 2015, 7, 8041-8052.

(3) González-Domínguez, J. M.; Ansón-Casaos, A.; Díez-Pascual, A. M.; Ashrafi, B.; Naffakh, M.; Backman, D.; Stadler, H.; Johnston, A.; Gómez, M.; Martínez, M. T. SolventFree Preparation of High-Toughness Epoxy - SWNT Composite Materials. ACS Appl. Mater. Interfaces 2011, 3, 1441-1450.

(4) Che, J.; Yuan, W.; Jiang, G.; Dai, J.; Lim, S. Y.; Chan-Park, M. B. Epoxy Composite Fibers Reinforced with Aligned Single-Walled Carbon Nanotubes Functionalized with Generation 0-2 Dendritic Poly(amidoamine). Chem. Mater. 2009, 21, 1471-1479.

(5) Randall, J. P.; Meador, M. A. B.; Jana, S. C. Tailoring Mechanical Properties of Aerogels for Aerospace Applications. ACS Appl. Mater. Interfaces 2011, 3, 613-626.

(6) Bekyarova, E.; Thostenson, E. T.; Yu, A.; Kim, H.; Gao, J.; Tang, J.; Hahn, H. T.; Chou, T.-W.; Itkis, M. E.; Haddon, R. C. Multiscale Carbon Nanotube-Carbon Fiber Reinforcement for Advanced Epoxy Composites. Langmuir 2007, 23, 3970-3974.

(7) Njuguna, J.; Pielichowski, K. Polymer Nanocomposites for Aerospace Applications: Properties. Adv. Eng. Mater. 2003, 5, 769-778.

(8) Chen, B.; Guizar-Sicairos, M.; Xiong, G.; Shemilt, L.; Diaz, A.; Nutter, J.; Burdet, N.; Huo, S.; Mancuso, J.; Monteith, A.; Vergeer, F.; Burgess, A.; Robinson, I. Three-Dimensional Structure Analysis and Percolation Properties of a Barrier Marine Coating. Sci. Rep. 2013, 3, 1177.

(9) Li, Q.; Guo, Y.; Li, W.; Qiu, S.; Zhu, C.; Wei, X.; Chen, M.; Liu, C.; Liao, S.; Gong, Y.; Mishra, A. K.; Liu, L. Ultrahigh Thermal Conductivity of Assembled Aligned Multilayer Graphene/Epoxy Composite. Chem. Mater. 2014, 26, 4459-4465.

(10) Zhang, C.; Hankett, J.; Chen, Z. Molecular Level Understanding of Adhesion Mechanisms at the Epoxy/Polymer Interfaces. ACS Appl. Mater. Interfaces 2012, 4 , 3730-3737.

(11) White, J. E.; Silvis, H. C.; Winkler, M. S.; Glass, T. W.; Kirkpatrick, D. E. Poly(hydroxyaminoethers): A New Family of Epoxy-Based Thermoplastics. Adv. Mater. (Weinheim, Ger.) 2000, 12, 1791-1800.

(12) Wegmann, A. Chemical Resistance of Waterborne Epoxy/Amine Coatings. Prog. Org. Coat. 1997, 32, 231-239. 
(13) Zhang, S.-Y.; Ding, Y.-F.; Li, S.-J.; Luo, X.-W.; Zhou, W.-F. Effect of Polymeric Structure on the Corrosion Protection of Epoxy Coatings. Corros. Sci. 2002, 44, 861-869.

(14) Augustyniak, A.; Tsavalas, J.; Ming, W. Early Detection of Steel Corrosion via "Turn-On" Fluorescence in Smart Epoxy Coatings. ACS Appl. Mater. Interfaces 2009, 1, 26182623.

(15) Macedo, M. C. S. S.; Margarit-Mattos, I. C. P.; Fragata, F. L.; Jorcin, J.-B.; Pébère, N.; Mattos, O. R. Contribution to a Better Understanding of Different Behaviour Patterns Observed with Organic Coatings Evaluated by Electrochemical Impedance Spectroscopy. Corros. Sci. 2009, 51, 1322-1327.

(16) Zhang, X.; He, Q.; Gu, H.; Colorado, H. A.; Wei, S.; Guo, Z. Flame-Retardant Electrical Conductive Nanopolymers Based on Bisphenol F Epoxy Resin Reinforced with Nano Polyanilines. ACS Appl. Mater. Interfaces 2013, 5, 898-910.

(17) Uddin, M. A.; Chan, H. P.; Chow, C. K. Thermal and Chemical Stability of a Spin-Coated Epoxy Adhesive for the Fabrication of a Polymer Optical Waveguide. Chem. Mater. 2004, 16, 4806-4811.

(18) Jin, H.; Miller, G. M.; Sottos, N. R.; White, S. R. Fracture and Fatigue Response of a SelfHealing Epoxy Adhesive. Polymer 2011, 52, 1628-1634.

(19) Erath, E. H.; Robinson, M. Colloidal Particles in the Thermosetting Resins. J. Polym. Sci., Part C: Polym. Symp. 1963, 3, 65-76.

(20) Erath, E. H.; Spurr, R. A. Occurrence of Globular Formations in Thermosetting Resins. J. Polym. Sci. 1959, 35, 391-399.

(21) Mijović, J.; Koutsky, J. A. Correlation between Nodular Morphology and Fracture Properties of Cured Epoxy Resins. Polymer 1979, 20, 1095-1107.

(22) Morgan, R. J.; O'Neal, J. E. The Microscopic Failure Processes and Their Relation to the Structure of Amine-Cured Bisphenol-A-Diglycidyl Ether Epoxies. J. Mater. Sci. 1977, 12, 1966-1980.

(23) Mijovic, J. S.; Koutsky, J. A. The Effect of Postcure Time on the Fracture Properties and Nodular Morphology of an Epoxy Resin. J. Appl. Polym. Sci. 1979, 23, 1037-1042.

(24) Racich, J. L.; Koutsky, J. A. Nodular Structure in Epoxy Resins. J. Appl. Polym. Sci. 1976, 20, 2111-2129.

(25) Houwink, R. The Strength and Modulus of Elasticity of Some Amorphous Materials, Related to Their Internal Structure. Trans. Faraday Soc. 1936, 32, 122-131.

(26) Sahagun, C. M.; Morgan, S. E. Thermal Control of Nanostructure and Molecular Network Development in Epoxy-Amine Thermosets. ACS Appl. Mater. Interfaces 2012, 4, 564 572.

(27) Kishi, H.; Naitou, T.; Matsuda, S.; Murakami, A.; Muraji, Y.; Nakagawa, Y. Mechanical Properties and Inhomogeneous Nanostructures of Dicyandiamide-Cured Epoxy Resins. J. Polym. Sci., Part B: Polym. Phys. 2007, 45, 1425-1434. 
(28) Dušek, K. Are Cured Thermoset Resins Inhomogeneous? Angew. Makromol. Chem. 1996, 240, 1-15.

(29) Vanlandingham, M. R.; Eduljee, R. F.; Gillespie, J. W. Relationships between Stoichiometry, Microstructure, and Properties for Amine-Cured Epoxies. J. Appl. Polym. Sci. 1999, 71, 699-712.

(30) Sahagun, C. M.; Knauer, K. M.; Morgan, S. E. Molecular Network Development and Evolution of Nanoscale Morphology in an Epoxy-Amine Thermoset Polymer. J. Appl. Polym. Sci. 2012, 126, 1394-1405.

(31) Gu, X.; Nguyen, T.; Oudina, M.; Martin, D.; Kidah, B.; Jasmin, J.; Rezig, A.; Sung, L.; Byrd, E.; Martin, J. W.; Ho, D. L.; Jean, Y. C. Microstructure and Morphology of AmineCured Epoxy Coatings Before and After Outdoor Exposures - An AFM Study. J. Coat. Technol. Res. 2005, 2, 547-556.

(32) Duchet, J.; Pascault, J. P. Do Epoxy-amine Networks Become Inhomogeneous at the Nanometric Scale? J. Polym. Sci., Part B: Polym. Phys. 2003, 41, 2422-2432.

(33) Haba, D.; Kaufmann, J.; Brunner, A. J.; Resch, K.; Teichert, C. Observation of Elastic Modulus Inhomogeneities in Thermosetting Epoxies Using AFM - Discerning Facts and Artifacts. Polymer 2014, 55, 4032-4040.

(34) Wu, W.; Bauer, B. J.; Su, W. Network Structure in Epoxies: 6. The Growth Process Investigated by Neutron Scattering. Polymer 1989, 30, 1384-1388.

(35) Matyi, R. J.; Uhlmann, D. R.; Koutsky, J. A. Structure of Glassy Polymers. VII. SmallAngle X-Ray Scattering from Epoxy Resins. J. Polym. Sci., Polym. Phys. Ed. 1980, 18, 1053-1063.

(36) Hill, G. A.; Rice, J. H.; Meech, S. R.; Craig, D. Q. M.; Kuo, P.; Vodopyanov, K.; Reading, M. Submicrometer Infrared Surface Imaging using a Scanning-Probe Microscope and an Optical Parametric Oscillator Laser. Opt. Lett. 2009, 34, 431-433.

(37) Lahiri, B.; Holland, G.; Centrone, A. Chemical Imaging Beyond the Diffraction Limit: Experimental Validation of the PTIR Technique. Small 2013, 9, 439-445.

(38) Dazzi, A.; Glotin, F.; Carminati, R. Theory of Infrared Nanospectroscopy by Photothermal Induced Resonance. J. Appl. Phys. (Melville, NY, U. S.) 2010, 107, 124519-1-124519-7.

(39) Kjoller, K.; Felts, J. R.; Cook, D.; Prater, C. B.; King, W. P. High-Sensitivity NanometerScale Infrared Spectroscopy Using a Contact Mode Microcantilever with an Internal Resonator Paddle. Nanotechnology 2010, 21, 185705.

(40) Deniset-Besseau, A.; Prater, C. B.; Virolle, M.-J.; Dazzi, A. Monitoring TriAcylGlycerols Accumulation by Atomic Force Microscopy Based Infrared Spectroscopy in Streptomyces Species for Biodiesel Applications. J. Phys. Chem. Lett. 2014, 5, 654-658.

(41) Mayet, C.; Dazzi, A.; Prazeres, R.; Ortega, J.-M.; Jaillard, D. In Situ Identification and Imaging of Bacterial Polymer Nanogranules by Infrared Nanospectroscopy. Analyst (Cambridge, U. K.) 2010, 135, 2540-2545. 
(42) Dušek, K.; Pleštil, J.; Lednický, F.; Luňák, S. Are Cured Epoxy Resins Inhomogeneous? Polymer 1978, 19, 393-397.

(43) DeBakker, C. J.; George, G. A.; St John, N. A.; Fredericks, P. M. The Kinetics of the Cure of an Advanced Epoxy Resin by Fourier Transform Raman and Near-IR Spectroscopy. Spectrochim. Acta 1993, 49A, 739-752.

(44) Lin-Vien, D.; Colthup, N. B.; Fateley, W. G.; Grasselli, J. G. The Handbook of Infrared and Raman Characteristic Frequencies of Organic Molecules; Academic Press Ltd: London, 1991.

(45) Chike, K. E.; Myrick, M. L.; Lyon, R. E.; Angel, S. M. Raman and Near-Infrared Studies of an Epoxy Resin. Appl. Spectrosc. 1993, 47, 1631-1635.

(46) Manfredi, L. B.; Ginés, M. J. L.; Benítez, G. J.; Egli, W. A.; Rissone, H.; Vázquez, A. Use of Epoxy-Phenolic Lacquers in Food Can Coatings: Characterization of Lacquers and Cured Films. J. Appl. Polym. Sci. 2005, 95, 1448-1458.

(47) Felts, J. R.; Cho, H.; Yu, M.-F.; Bergman, L. A.; Vakakis, A. F.; King, W. P. Atomic Force Microscope Infrared Spectroscopy on $15 \mathrm{~nm}$ Scale Polymer Nanostructures. Rev. Sci. Instrum. 2013, 84, 023709.

(48) Morgan, R. J.; O'Neal, J. E.; Miller, D. B. The Structure, Modes of Deformation and Failure, and Mechanical Properties of Diaminodiphenyl Sulphone-Cured Tetraglycidyl 4,4'-Diaminodiphenyl Methane Epoxy. J. Mater. Sci. 1979, 14, 109-124.

(49) Morgan, R. J.; O'Neal, J. E. The Durability of Epoxies. Polym.-Plast. Technol. Eng. 1978, 10, 49-116.

(50) Nguyen, T.; Gu, X.; Vanlandingham, M.; Byrd, E.; Ryntz, R.; Martin, J. W. Degradation Modes of Crosslinked Coatings Exposed to Photolytic Environment. J. Coat. Technol. Res. 2013, 10, 1-14.

(51) Nicodemo, L.; Bellucci, F.; Marcone, A.; Monetta, T. Water and Oxygen Transport as Performance Parameters of Paint Films. J. Membr. Sci. 1990, 52, 393-403.

(52) Gupta, V. B.; Drzal, L. T.; Rich, M. J. The Physical Basis of Moisture Transport in a Cured Epoxy Resin System. J. Appl. Polym. Sci. 1985, 30, 4467-4493.

(53) Morsch, S.; Lyon, S.; Greensmith, P.; Smith, S. D.; Gibbon, S. R. Water Transport in an Epoxy-Phenolic Coating. Prog. Org. Coat. 2015, 78, 293-299.

(54) Cuthrell, R. E. Epoxy Polymers. II. Macrostructure. J. Appl. Polym. Sci. 1968, 12, 12631278.

(55) Bai, S. J. Crosslink Distribution of Epoxy Networks Studied by Small-Angle Neutron Scattering. Polymer 1985, 26, 1053-1057.

(56) Aspbury, P. J.; Wake, W. C. The Supermolecular Structures Found in Cured Epoxy Resins. Br. Polym. J. 1979, 11, 17-27. 
(57) Sherman, C. L.; Zeigler, R. C.; Verghese, N. E.; Marks, M. J. Structure-Property Relationships of Controlled Epoxy Networks with Quantified Levels of Excess Epoxy Etherification. Polymer 2008, 49, 1164-1172.

\section{TABLE OF CONTENTS GRAPHIC}

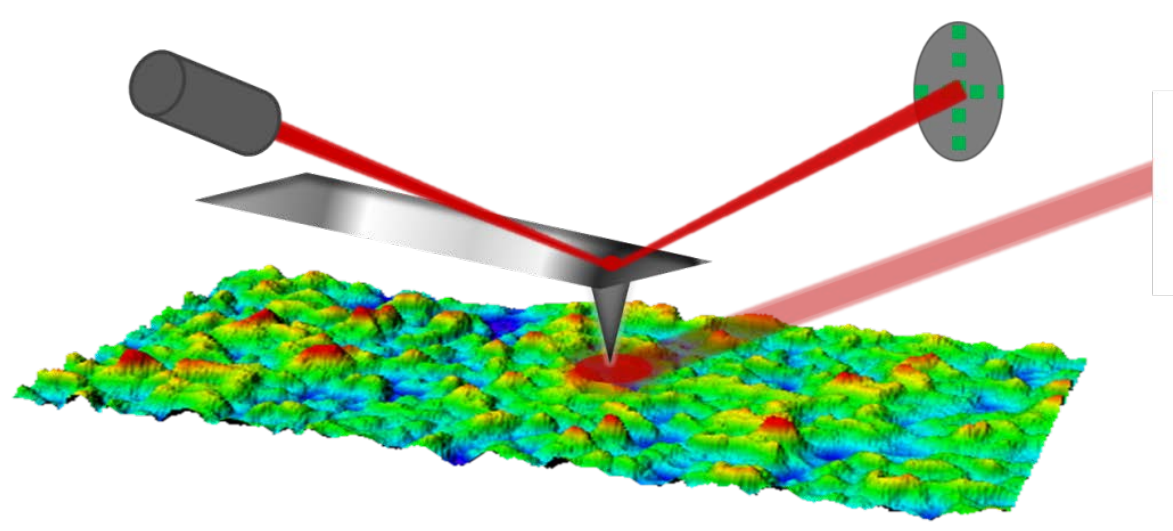

